\title{
Transporte de Agrotóxicos em lavoura de ARRoz IRrigado sob TRÊS MANEJOS DE IRRIGAÇÃO ${ }^{1}$
}

\author{
Pesticide Transport in Rice Field under Three Irrigation Managements
}

\author{
MARTINI, L.F.D. ${ }^{2}$, AVILA, L.A. ${ }^{3}$, CASSOL, G.V. ${ }^{4}$, ZANELLA, R. ${ }^{5}$, MACHADO, S.L.O. ${ }^{6}$, \\ MARQUES, M.S. ${ }^{5}$ e DE VICARI, M. ${ }^{7}$
}

\begin{abstract}
RESUMO - O cultivo de arroz irrigado no Rio Grande do Sul caracteriza-se pela permanência de lâmina de irrigação sobre o solo, o que ocasiona perdas de agrotóxicos na ocorrência de chuvas; portanto, o adequado manejo de irrigação pode influenciar na redução do transporte destes para o ambiente. O objetivo deste trabalho foi avaliar o efeito de diferentes manejos de irrigação no extravasamento da água e no transporte e persistência de clomazone, thiamethoxam, imidacloprid, trifloxystrobin e propiconazol em lavoura de arroz irrigado. Os tratamentos arranjados em esquema fatorial consistiram nos manejos de irrigação por inundação contínua, intermitente e por banhos (fator A) e pelos agrotóxicos mencionados (fator B). Determinou-se o volume total de água extravasada e a taxa de dissipação e transporte desses agrotóxicos. Devido ao maior armazenamento de água da chuva, quando comparadas com a irrigação contínua, as irrigações intermitente e por banhos proporcionaram diminuição de 53 e 95\% do volume de água perdida, resultando, respectivamente, em redução de 49 e 64\% na massa total de agrotóxicos transportados para o ambiente, em relação ao total aplicado na lavoura. A massa de agrotóxico transportada não ultrapassou 3\% do total aplicado, e as maiores concentrações de agrotóxicos em água ocorreram próximo à sua aplicação. Com base nesses resultados, salienta-se que os manejos de irrigação intermitente e por banhos minimizam o transporte de agrotóxicos para o ambiente.
\end{abstract}

Palavras-chave: contaminação ambiental, escoamento superficial, meia-vida de dissipação em água.

ABSTRACT - Rice crop in the state of Rio Grande do Sul is characterized by the presence of water layer on the soil, which can cause pesticide runoff during the occurrence of rainfall. Thus, proper irrigation management can reduce pesticide transport into the environment. The objective of this study was to evaluate the effect of different irrigation managements on water runoff, transport and dissipation of clomazone, thiamethoxam, imidacloprid, trifloxystrobin, and propiconazol. The treatments were arranged in a factorial scheme and consisted of continuous flooding, intermittent flooding, and flushing irrigation (factor A) and by the application of the pesticides listed above (factor B). Total water runoff, and pesticide transport and dissipation rate were evaluated. Due to the larger rainfall storage, compared with continuous flooding, intermittent flooding and flushing irrigation provided a reduction of 53 and 95\% of water runoff, resulting, respectively, in a reduction of 49 and $64 \%$ of the total mass transported into the environment in relation to the total applied in the field. The pesticide mass transported was lower than 3\% of the total amount applied. Based on these results, it could be concluded that intermittent flooding and flushing irrigation minimize pesticide transport into the environment. Since the highest pesticide concentrations occur close to application time, it is of fundamental importance to conduct proper irrigation management providing maximum permanence in the environment.

Keywords: environmental contamination, half-life water dissipation, runoff.

1 Recebido para publicação em 1.11.2011 e aprovado em 21.5.2012.

Parte da dissertação de mestrado do primeiro autor.

2 Doutorando, Programa de Pós-Graduação em Fitossanidade, Universidade Federal de Pelotas - UFPel, Bolsista CAPES; ${ }^{3}$ Professor Adjunto, Dep. de Fitossanidade, UFPel, Caixa Postal 354, 96010-900 Pelotas-RS, Brasil, Bolsista CNPq, $<$ laavilabr@gmail.com>; ${ }^{4}$ Mestrando(a), Programa de Pós-Graduação em Fitossanidade, UFPel, Bolsista CAPES; ${ }^{5}$ Professor Associado, Dep. de Química, Universidade Federal de Santa Maria - UFSM, Bolsista CNPq; ${ }^{6}$ Professor Titular, Dep. de Fitossanidade, UFSM; ${ }^{7}$ Doutoranda, Programa de Pós-Graduação em Química, UFSM.

Planta Daninha, Viçosa-MG, v. 30, n. 4, p. 799-808, 2012 


\section{INTRODUÇÃO}

O moderno sistema produtivo de arroz irrigado é caracterizado pela estabilidade de produção e elevada produtividade. A maior expressão do potencial produtivo ocorre devido à irrigação por inundação e à ampla utilização de agrotóxicos, os quais são utilizados para minimizar os efeitos de agentes como plantas daninhas, insetos e doenças (Marchezan et al., 2007).

Parte dos agrotóxicos aplicados não atinge o alvo biológico, estando sujeita a diferentes destinos no ambiente, como degradação química, fotólise, degradação microbiológica, transporte por volatilização, lixiviação e escoamento superficial (Harper, 1994). O escoamento superficial pode ocasionar contaminação ambiental de mananciais hídricos, podendo entrar na cadeia trófica através da contaminação direta da água potável (Stone, 2005) e/ou bioacumulação em peixes (Bretaud et al., 2000).

Em áreas de cultivo de arroz irrigado, a contaminação de corpos hídricos possui significativa importância, pois a maioria dessas áreas localiza-se em locais com topografia mais baixa, com lençol freático próximo à superficie do solo, e/ou posicionada às margens de córregos, riachos ou rios. Esses fatores fazem da lavoura arrozeira uma potencial fonte poluidora de recursos hídricos, o que pode, dessa forma, afetar tanto o ecossistema aquático quanto a própria qualidade da água de mananciais hídricos superficiais, principalmente.

O cultivo de arroz irrigado no Estado do Rio Grande do Sul é, na maior parte da área, conduzido sob irrigação por inundação, caracterizada pela permanência de uma lâmina de água sobre a superficie do solo (IRGA, 2009). Esse manejo de irrigação, amplamente adotado pelos produtores, caracteriza-se pela contínua entrada de água (ou manejo contínuo), gerando menor risco de déficit hídrico, que pode causar perdas de produtividade, além de garantir melhor controle de plantas daninhas (Stone, 2005).

A manutenção de uma lâmina de irrigação contínua sobre o solo pode ocasionar maiores perdas por percolação ao longo do perfil do solo
(Walker, 1999), maior demanda de água para a irrigação (Stone, 2005; Watanabe et al., 2006, 2007) e facilitar a ocorrência do escoamento superficial da água do interior da lavoura em ocasiões de chuvas. Neste último tipo de perda de água podem estar contidos agrotóxicos na solução e/ou adsorvidos a coloides do solo em suspensão (Watanabe et al., 2006, 2007; Chang et al., 2007; Phong et al., 2008), promovendo maior risco de contaminação ambiental. Trabalhos recentes sobre o monitoramento da qualidade de água identificaram contaminações de fontes superficiais em diferentes regiões orizícolas do Estado do Rio Grande do Sul (Silva et al., 2009): região central (Bortoluzzi et al., 2006; Marchezan et al., 2007) e região sul (Grutzmacher et al., 2008).

Existem alternativas de manejo de água que podem reduzir o transporte de agrotóxicos para o ambiente, como a irrigação intermitente e a irrigação a banho, entre outras. A irrigação intermitente em arroz irrigado, além de manter elevados os niveis de produtividade (Belder, 2004), permite economia de água para irrigação (Borrell et al., 1997; Stone, 2005) e redução do transporte de alguns agrotóxicos (Watanabe et al., 2006). Essa economia é proporcionada pelo melhor aproveitamento (captação) das precipitações (Borrell et al., 1997; Toescher et al., 1997) e diminuição das perdas por escoamento superficial (Stone, 2005; Watanabe et al., 2006, 2007) e das perdas por percolação (Borrell et al., 1997; Tuong \& Bhuiyan, 1999; Tabbal et al., 2002; Stone, 2005; Tuong et al., 2005). Essas alternativas devem ser testadas e as perdas quantificadas, a fim de determinar a eficiência dessas tecnologias na redução do transporte de agrotóxicos nas condições de clima da lavoura de arroz irrigado no Brasil.

O objetivo do presente estudo foi avaliar o efeito dos manejos de irrigação com lâmina continua, intermitente e por banhos sobre o extravasamento de água e transporte e dissipação de clomazone, thiamethoxam, imidacloprid, trifloxystrobin e propiconazol.

\section{MATERIAL E MÉTODOS}

O experimento foi realizado no ano agrícola de 2008/09, na área experimental do 
Departamento de Fitotecnia da Universidade Federal de Santa Maria, Santa Maria-RS. O solo é classificado como Planossolo Hidromórfico Eutrófico Arênico (Unidade de Mapeamento Vacacai), com classe textural franco-siltosa, com as seguintes características: $\mathrm{pH}_{\text {água }}(1: 1)$ $=5,1$; teor de argila $=210 \mathrm{~g} \mathrm{~kg}^{-1}$; teor de matéria orgânica $=1,9 \% ; \mathrm{P}=18 \mathrm{mg} \mathrm{dm}^{-3} ; \mathrm{K}=36 \mathrm{mg} \mathrm{dm}^{-3}$; $\mathrm{Ca}=4,8 \mathrm{cmol}_{\mathrm{c}} \mathrm{dm}^{-3} ; \mathrm{Mg}=1,8 \mathrm{cmol}_{\mathrm{c}} \mathrm{dm}^{-3}$; $\mathrm{Al}=1,7 \mathrm{cmol}_{\mathrm{c}} \mathrm{dm}^{-3} ;$ e índice SMP $=6,4$.

O experimento foi conduzido no delineamento inteiramente casualizado com quatro repetições. Os tratamentos foram arranjados no esquema fatorial, em que o fator A foi composto por três manejos de irrigação: irrigação por inundação contínua, irrigação intermitente e irrigação por banhos. $\mathrm{O}$ fator $\mathrm{B}$ consistiu de diferentes agrotóxicos: clomazone, imidacloprid, thiamethoxam, trifloxystrobin e propiconazol, cujas características físico-químicas estão listadas na Tabela 1.

No manejo contínuo, a lâmina de irrigação foi mantida a $10 \mathrm{~cm}$ durante todo o ciclo da cultura. No manejo intermitente, iniciou-se com uma lâmina de $10 \mathrm{~cm}$ e em seguida permitiu-se a evapotranspiração total desta, até que o solo ficasse na condição de encharcamento; a partir desse momento, foi efetuada a reposição da lâmina de irrigação a $10 \mathrm{~cm}$, totalizando três reposições durante o ciclo. No manejo por banhos, foram aplicadas somente lâminas de $30 \mathrm{~mm}$ de volume de água, totalizando sete irrigações. O manejo de irrigação por banhos foi orientado pelas condições meteorológicas da região, pelo estádio fenológico da cultura e pelas previsões de chuva; foi calculado o requerimento diário de água, através do cálculo da evapotranspiração, pela equação de Penman-Monteith. Nos três tratamentos, a irrigação foi interrompida quando as plantas de arroz se encontravam no estádio R7 (110 dias após a emergência $\mathrm{DAE})$, conforme escala fenológica proposta por Counce et al. (2000).

As unidades experimentais constituíramse de $57 \mathrm{~m}^{2}$ de área útil $(15 \times 3,8 \mathrm{~m})$ e foram isoladas por taipas. A semeadura foi realizada no dia 3/11/2008, na densidade de $120 \mathrm{~kg} \mathrm{ha}^{-1}$ de sementes do cultivar IRGA $422 \mathrm{CL}$, em sistema de cultivo mínimo. As sementes foram previamente tratadas com os inseticidas thiamethoxam (350 $\left.\mathrm{g} \mathrm{L}^{-1}\right)$ e imidacloprid (600 $\left.\mathrm{g} \mathrm{L}^{-1}\right)$ nas doses de 0,3 e $0,08 \mathrm{~L}$ p.c. $100 \mathrm{~kg}$ de sementes ${ }^{-1}$, respectivamente. As sementes também foram tratadas com o protetor dietholate $\left(800 \mathrm{~g} \mathrm{~L}^{-1}\right)$ na dose de $1 \mathrm{~L}$ p.c. $100 \mathrm{~kg}$ de sementes ${ }^{-1}$. Os demais tratos culturais, como adubação e controle de pragas e doenças, foram efetuados conforme as recomendações da pesquisa da cultura, para obtenção de elevadas produtividades (SOSBAI, 2007).

O controle de plantas daninhas foi feito pela aplicação dos herbicidas clomazone (500 g i.a. $\mathrm{L}^{-1}$ ), na dose de 2 L p.c. ha-1, e glyphosate (360 g e.a. $\mathrm{L}^{-1}$ ), na dose de 3 L p.c. ha ${ }^{-1}$ ambos em pré emergência, e imazethapyr e imazapic (75 e 25 g i.a. L), na dose de $1 \mathrm{~L}$ p.c. ha ${ }^{-1}$, em pós-emergência, no estádio V3 - V4. Os herbicidas foram aplicados com um pulverizador costal pressurizado a $\mathrm{CO}_{2}$, utilizando pontas Teejet $110015 \mathrm{XR}$ sob pressão de 1,4 bar, resultando em volume de calda de $150 \mathrm{~L} \mathrm{ha}^{-1}$. A irrigação foi iniciada no dia seguinte à aplicação do herbicida pósemergente.

Tabela 1 - Propriedades físico-químicas do herbicida clomazone, dos inseticidas imidacloprid e thiamethoxam e dos fungicidas trifloxystrobin e propiconazol. 2009

\begin{tabular}{|l|c|c|c|c|c|}
\hline & Clomazone $^{1 /}$ & Imidacloprid $^{2 /}$ & Thiamethoxam $^{2 /}$ & Trifloxystrobin $^{2 /}$ & Propiconazol $^{2 /}$ \\
\hline P. molec. $\left(\mathrm{g} \mathrm{mol}^{-1}\right)$ & 239,7 & 255,7 & 291,7 & 408,4 & 342,2 \\
\hline Solub. em água $\left(\mathrm{mg} \mathrm{L}^{-1}\right)$ & 1.100 & 610 & 4.100 & 610 & 100 \\
\hline $\mathrm{K}_{\mathrm{ow}}$ & 2,54 & 0,57 & $-0,13$ & 4,5 & 3,72 \\
\hline $\mathrm{K}_{\mathrm{oc}}\left(\mathrm{mL} \mathrm{g}^{-1}\right)$ & 300 & 225 & 70 & $1.642-3.745$ & 950 \\
\hline $\mathrm{pKa}$ & - & - & - & - & 1,09 \\
\hline $\mathrm{PV}(\mathrm{mPa})$ & $1,92 \times 10^{-2}$ & $4 \times 10^{-7}$ & $6,610^{-6}$ & $3,4 \times 10^{-3}$ & $2,7 \times 10^{-2}$ \\
\hline Meia-vida em campo (dias) & 24 & 191 & 51 & $4,2-9,5$ & $29-70$ \\
\hline
\end{tabular}

1/ (Senseman, 2007). ㄴ/ (Tomlin, 2004). 
A irrigação foi realizada de forma automatizada, distribuída independentemente em cada unidade experimental, através do uso de boias. A quantificação do volume de água aplicado foi efetuada por meio da leitura de hidrômetros instalados em cada unidade experimental. Diariamente, foram efetuadas leituras dos hidrômetros e da altura da lâmina de irrigação. Para quantificação do volume de água extravasado, foi instalado sistema de drenagem individual por parcela, o qual consistiu em uma chapa com três fileiras de 17 furos circulares; nos furos centrais, foram conectadas mangueiras a uma caixa-d'água de capacidade de $500 \mathrm{~L}$, totalizando a coleta de 1/17 do volume total de água extravasada. Na ocasião de chuvas com ocorrência de extravasamento, o volume de água foi quantificado e logo coletado para análise, com o objetivo de avaliar o transporte dos agrotóxicos. O volume de cada ocorrência de chuvas foi quantificado por um pluviômetro instalado no centro do experimento.

Para análise de meia-vida dos ingredientes ativos, foram feitas amostragens sistemáticas no interior de cada parcela aos $1,3,5$, $7,10,16,25,35,41,52,74,82$ e 93 dias após o início da irrigação (DAII), o que correspondeu a $16,19,21,23,26,32,41,51,57,68,90,98$ e 109 DAE, respectivamente. As concentrações dos agrotóxicos detectados na água de inundação foram convertidas em $10 \mathrm{~cm}$ de lâmina, a fim de isolar o efeito de diluição, em decorrência da diferenciada altura da lâmina de irrigação verificada entre os tratamentos.

A quantidade total de agrotóxicos transportados para o ambiente foi determinada para os três manejos de irrigação, porém as taxas de dissipação e a meia-vida dos agrotóxicos foram calculadas apenas para os manejos que continham lâmina de irrigação sobre o solo, ou seja, manejos de irrigação contínuo e intermitente.

As amostras de água coletadas foram acondicionadas em frascos âmbar de $1 \mathrm{~L}$ de capacidade e encaminhadas ao Laboratório de Análise de Resíduos de Pesticidas (LARPUFSM). Essas amostras foram acidificadas e pré-concentradas em cartuchos contendo $500 \mathrm{mg}$ do adsorvente STRATA $\mathrm{C}_{18}$, sendo a eluição executada por duas vezes com $500 \mu \mathrm{L}$ de metanol. A detecção e a quantificação dos agrotóxicos clomazone, thiamethoxam e imidacloprid foram realizadas utilizando-se HPLC-UV, a $220 \mathrm{~nm}$, munida de uma coluna Bondesil C18 (250 x 4,6 mm d.i.; $5 \mu \mathrm{m}$ ), com fase móvel constituída de metanol e água (60:40 v.v. $\left.{ }^{-1}\right)$, ajustada a $\mathrm{pH} 4,0$ com ácido

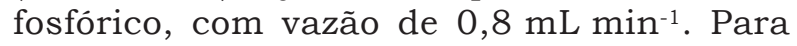
trifloxystrobin e propiconazol, o procedimento de extração da amostra foi idêntico, variando somente o método analítico, o qual foi o GC-ECD, utilizando-se volume de injeção de $1 \mu \mathrm{L}$ do volume eluído, em coluna capilar apolar DB-5 (5\% fenil e 95\% metilpolisiloxano) de $30 \mathrm{~m}$ de comprimento, 0,25 $\mathrm{mm}$ de d.i. e $0,25 \mu \mathrm{m}$ de espessura de filme, empregando gás hélio para o arraste, com vazão inicial de $1,3 \mathrm{~mL} \mathrm{~min}^{-1}$ e temperatura de $300{ }^{\circ} \mathrm{C}$ do detector.

Foi obtida a constante de dissipação de primeiro grau (Kp) para os agrotóxicos testados, por meio da plotagem do Ln (concentração final/concentração inicial). O valor da meiavida do herbicida clomazone foi calculado usando a equação:

$$
t / 2=\operatorname{Ln} 2 / k p
$$

em que $k p$ significa a constante de dissipação de primeira ordem, bem como a taxa de dissipação dos agrotóxicos na água e no solo, conforme supracitado.

Os dados referentes às constantes da taxa de dissipação dos agrotóxicos $\left(\mathrm{k}_{\mathrm{p}}\right)$, quantidade de água aplicada $\left(\mathrm{m}^{3} \mathrm{ha}^{-1}\right)$, quantidade de água extravasada $\left(\mathrm{m}^{3} \mathrm{ha}^{-1}\right)$, quantidade total de agrotóxicos $\left(\mathrm{g} \mathrm{ha}^{-1}\right)$ que extravasou juntamente com a água e porcentagem de agrotóxico transportado em relação ao total aplicado foram inicialmente testados quanto à normalidade e homogeneidade da variância dos dados. As variáveis transporte de agrotóxicos em gramas e porcentagem destes transportados em relação ao total aplicado foram transformadas para:

$$
y t=a \sin \sqrt{(y+0.5) / 100}
$$

em que $y t$ é a variável transformada e $y$, a variável não transformada.

Logo, todas as variáveis foram submetidas à análise da variância; no caso de diferença 
significativa entre os manejos de irrigação e agrotóxicos, as médias foram comparadas pelo teste de Tukey $(\leq 0,05)$.

\section{RESULTADOS E DISCUSSÃO}

O volume de água perdido por escoamento superficial foi significativamente menor nos manejos de irrigação por banhos $\left(215 \mathrm{~m}^{3} \mathrm{ha}^{-1}\right)$ intermitente $\left(2.145 \mathrm{~m}^{3} \mathrm{ha}^{-1}\right)$, quando comparados à inundação por lâmina contínua (4.554 $\left.\mathrm{m}^{3} \mathrm{ha}^{-1}\right)$. O menor estravasamento nos tratamentos por banhos e intermitente ocorreu devido ao armazenamento de maior volume de água da chuva no interior das parcelas. A altura da lâmina de água nesses dois tratamentos na maior parte do período experimental foi menor que no tratamento com irrigação contínua (Figura 1), ficando assim uma borda livre (diferença entre a altura da lâmina de água e a da taipa), que proporciona o armazenamento de água da chuva no interior da parcela, reduzindo assim o extravasamento. Esses resultados corroboram os estudos realizados por Watanabe et al. (2006, 2007), Chang et al. (2007) e Phong et al. (2008).
Com base na diferença entre a precipitação total do período de cultivo de $513 \mathrm{~mm}$ e o volume de água extravasado, os manejos de irrigação por banhos e intermitente proporcionaram, respectivamente, armazenamento de $492 \mathrm{~mm}\left(4.915 \mathrm{~m}^{3} \mathrm{ha}^{-1}\right)$ e $299 \mathrm{~mm}$ $\left(2.985 \mathrm{~m}^{3} \mathrm{ha}^{-1}\right)$, em comparação com a irrigação contínua, a qual somente armazenou $58 \mathrm{~mm}$. Em valores percentuais, os manejos de irrigação por banhos e intermitente proporcionaram, respectivamente, a captação de 96 e $58 \%$ do volume total de chuvas e possibilitaram redução de 95 e 53\% no volume de água extravasado para fora da lavoura, quando comparado com a irrigação contínua.

Quanto à dissipação dos agrotóxicos, não foi verificada diferença significativa entre os manejos de irrigação para clomazone, thiamethoxam e imidacloprid. Detectaram-se traços desses agrotóxicos durante o período entre a aplicação deles e os 93 dias após o início da irrigação (DAII) (data-limite do monitoramento) em ambos os tratamentos, exceto para thiamethoxam, o qual não foi detectado a partir dos 41 DAII (Figura 2).

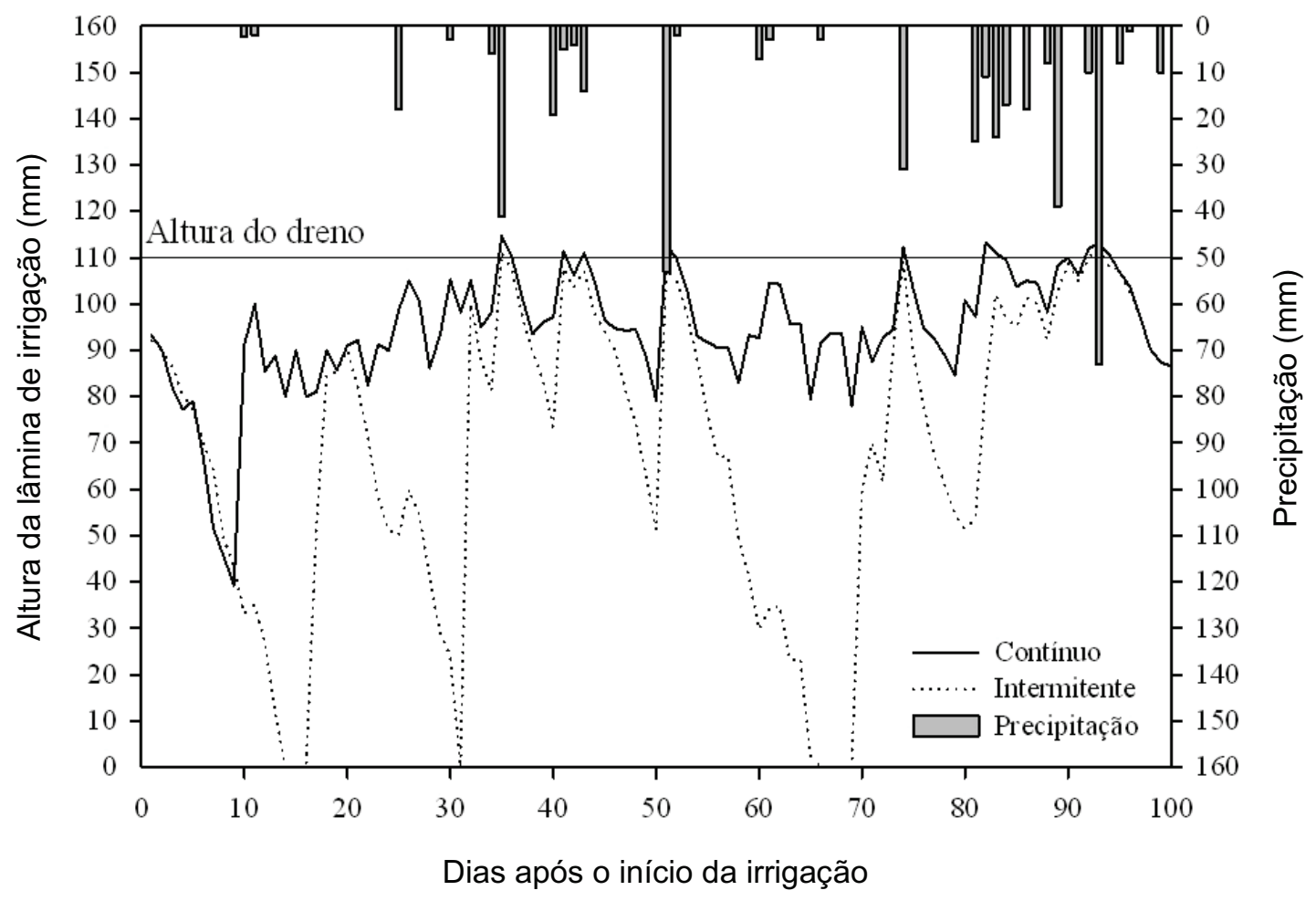

Figura 1 - Altura da lâmina de água dos manejos de irrigação contínuo e intermitente e precipitação do período, em dias após o início da irrigação. Santa Maria-RS. 2009. 


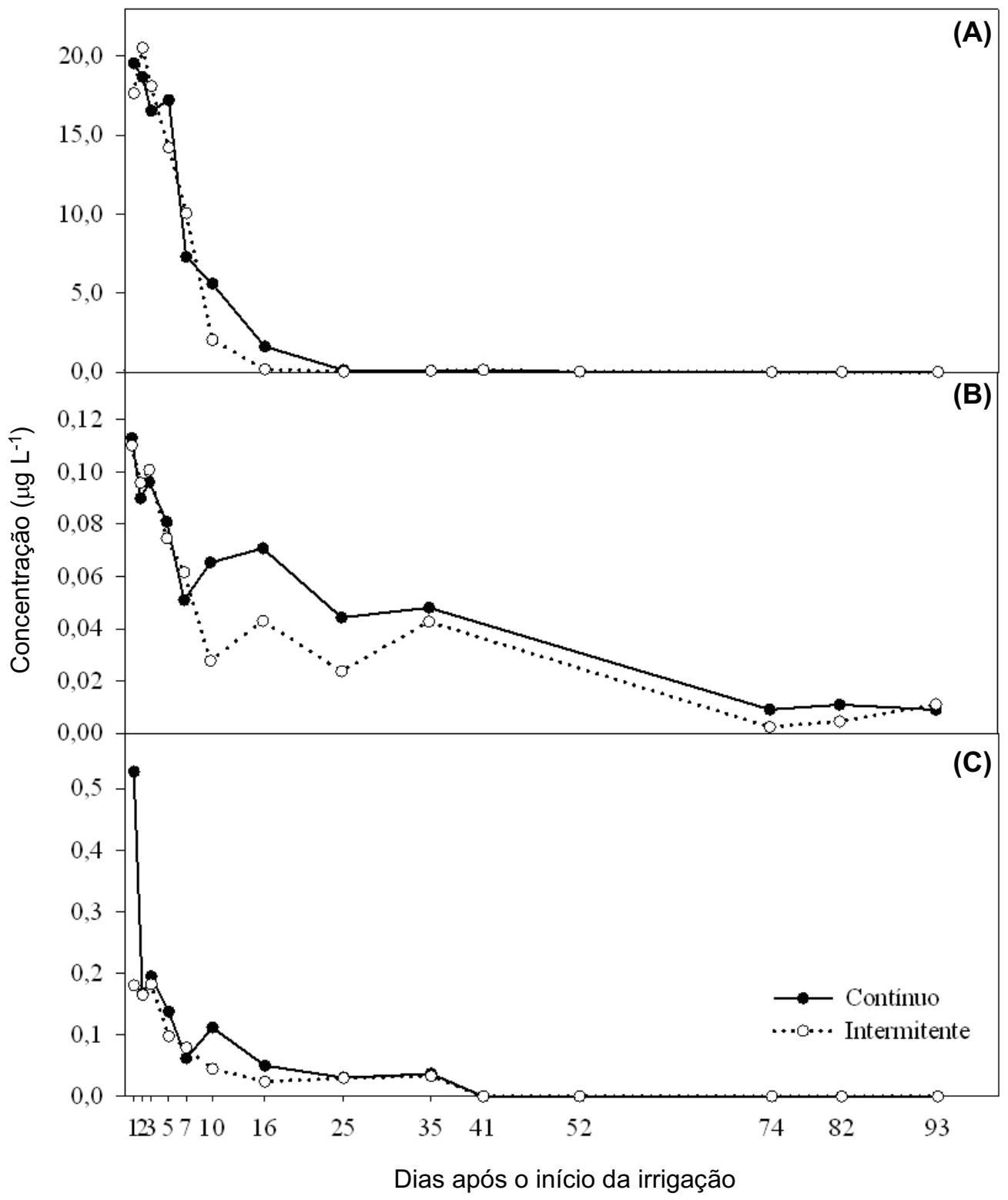

Figura 2 - Curva de dissipação do herbicida clomazone (A) e dos inseticidas thiamethoxam (B) e imidacloprid (C), em relação aos manejos de irrigação contínuo e intermitente. Santa Maria-RS. 2009.

A máxima concentração dos agrotóxicos em solução ocorreu logo após a sua aplicação, porém não foi verificada diferença significativa entre os manejos de irrigação para nenhum agrotóxico avaliado (Figura 2). A maior concentração de agrotóxicos logo após a aplicação foi também observada por outros pesquisadores (Nakano et al., 2004; Watanabe et al., 2006, 2007) e se deve ao fato de que, logo depois da aplicação, os agrotóxicos normalmente têm rápida dissipação, tornando as primeiras avaliações aquelas com maior concentração.
O herbicida clomazone apresentou máxima concentração para o manejo contínuo, 24 horas após o início da irrigação, com $19,56 \mu \mathrm{g} \mathrm{L}^{-1}$, e aos 2 DAII para o manejo intermitente, com 20,54 $\mu \mathrm{g} \mathrm{L}^{-1}$ (Figura 2A). Para os inseticidas, o pico de máxima concentração, independentemente do manejo de irrigação, ocorreu no dia 01 (DAII), com concentrações máximas de 0,53 e $0,18 \mu \mathrm{g} \mathrm{L}^{-1}$ para thiamethoxam (Figura 2B) e 0,11 e 0,11 para imidacloprid (Figura 2C), respectivamente nos manejos de irrigação contínua e intermitente. 
Esses resultados concordam com o estudo de Phong et al. (2009), os quais verificaram que a máxima concentração de imidacloprid ocorreu 24 horas após o início da irrigação. Apesar de não significativa, a diferença de concentração de thiamethoxam entre os manejos de irrigação pode ser atribuída à sua alta solubilidade em água (4.100 $\mathrm{mg} \mathrm{L}^{-1}$ ) (Tabela 1), facilitando a solubilização na presença de maior volume de água e, consequentemente, maior disponibilização dele na água de irrigação.

A máxima concentração dos agrotóxicos próximo à sua aplicação denota a necessidade de prevenção de escoamento superficial, principalmente logo após o início da irrigação. Uma ferramenta para manter essa água dentro da lavoura é através da manutenção de uma lâmina de água mais baixa na fase inicial do cultivo, deixando assim uma borda livre ainda maior para armazenar a água da chuva e reduzir o extravasamento (Watanabe et al., 2007).

Quanto aos inseticidas imidacloprid e thiamethoxam, não foi possivel determinar sua taxa de dissipação em água devido ao baixo ajuste da equação de dissipação, impossibilitando obter o valor Kp. Esse fato pode estar relacionado ao seu modo de aplicação via tratamento de sementes, não havendo assim uma concentração inicial conhecida do inseticida em água. No tratamento de sementes, o contato direto do agrotóxico com o solo promove maior sorção, o que retarda a sua disponibilidade na solução do solo, e consequentemente, a sua dissolução na água de irrigação. Da mesma forma que os inseticidas, não foi possivel calcular a meia-vida em água dos fungicidas trifloxystrobin e propiconazol, pois estes foram aplicados diretamento sobre o dossel foliar da cultura no estádio R3, impossibilitando a determinação da concentração inicial desses agrotóxicos em água. Dessa forma, impossibilitou-se a comparação da meia-vida de dissipação entre os agrotóxicos testados, sendo somente demonstrados valores correspondentes ao herbicida clomazone, o qual obteve meia-vida de dissipação em água de 3,8 dias em média (Tabela 2), não diferindo entre os manejos de irrigação. A meia-vida calculada neste experimento foi ligeiramente inferior à observada em outros estudos, como o de Quayle et al. (2006), que encontraram
7,2 dias, e o de Santos et al. (2008), que observaram meia-vida em água de cinco dias.

Com relação ao transporte de agrotóxicos para o ambiente, observa-se que ocorreram dez, nove e cinco eventos de extravasamento durante todo o período de cultivo do arroz para os manejos de irrigação contínuo, intermitente e por banhos, respectivamente (Tabela 3). Para todos os eventos de extravasamento ocorridos durante o período de cultivo, a maior concentração de agrotóxicos transportados ao ambiente foi verificada aos 26 DAII, com 0,602, 3,866 e $1,832 \mu \mathrm{g} \mathrm{L}^{-1}$, para clomazone, imidacloprid e thiamethoxam, respectivamente. O referido evento ocorreu apenas no manejo de irrigação contínuo. Quanto ao manejo intermitente, o primeiro evento de extravasamento aconteceu aos 35 DAII, com concentrações de 0,073, 0,046 e 0,032 $\mu \mathrm{g} \mathrm{L}^{1}$, para clomazone, imidacloprid e thiamethoxam, respectivamente. O primeiro evento de extravasamento do manejo de irrigação por banhos com traços detectáveis de agrotóxicos ocorreu apenas aos 85 DAII, com concentrações de 0,051, 0,014 e $0,121 \mu \mathrm{g} \mathrm{L}^{-1}$, para clomazone, imidacloprid e thiamethoxam, respectivamente. $\mathrm{O}$ atraso na ocorrência de extravasamento pelos manejos de irrigação intermitente e por banhos propiciou maior período para degradação dos agrotóxicos, em comparação ao manejo contínuo.

Da mesma forma que os agrotóxicos mencionados, para os fungicidas trifloxystrobin e propiconazol - os quais foram aplicados no estádio R3, no dia 2 de fevereiro de 2009 (ou aos 66 DAII) - foram observadas altas concentrações na água transportada, em comparação aos demais agrotóxicos (Tabela 4). Esse fato pode ser explicado em função da ocorrência de extravasamento nove dias após a aplicação, ou seja, pouco tempo para a sua degradação.

Tabela 2 - Constante de dissipação de primeiro grau $(k p)$ e meia-vida de dissipação em água $\left(\mathrm{DT}_{50}\right)$ do herbicida clomazone, nos manejos de irrigação contínuo e intermitente. Santa Maria-RS. 2009

\begin{tabular}{|l|l|c|}
\hline \multicolumn{1}{|c|}{ Tratamento } & $k p$ & $\mathrm{DT}_{50}$ \\
\hline Manejo contínuo & $0,180^{\mathrm{ns}}$ & 3,85 \\
\hline Manejo intermitente & 0,182 & 3,83 \\
\hline Média & 0,181 & 3,84 \\
\hline
\end{tabular}

${ }^{\text {ns }}$ sem efeito significativo. 


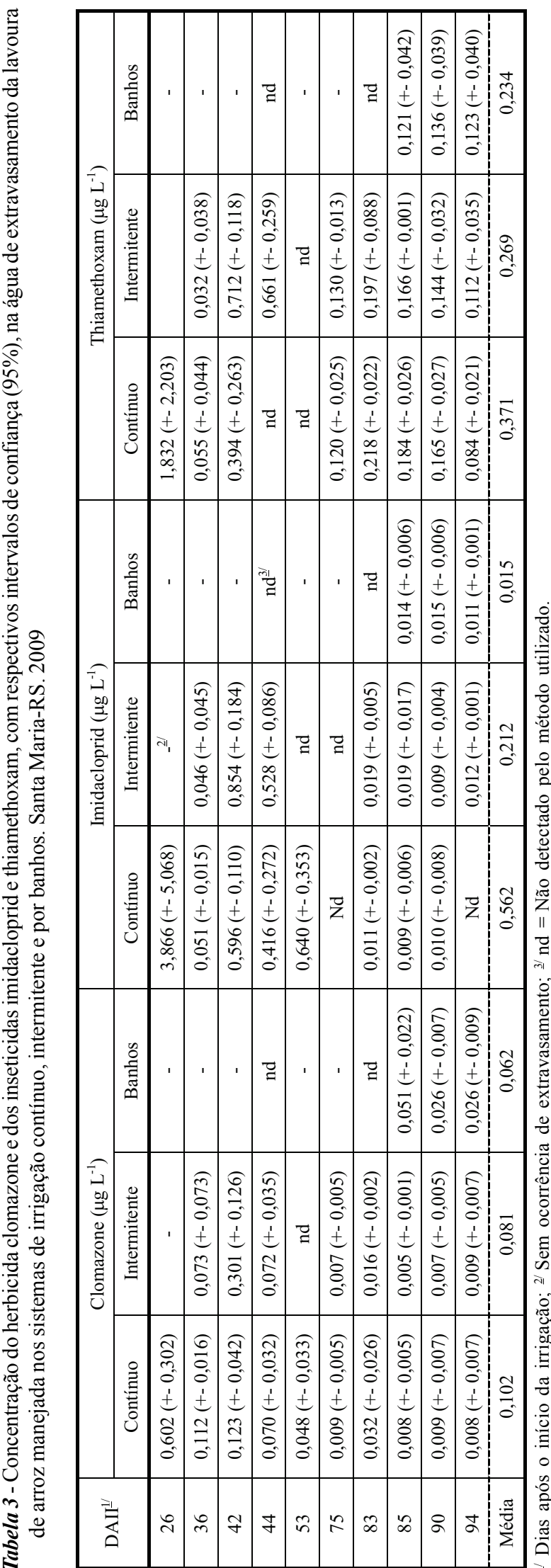

No total, foram cinco eventos de extravasamento dos manejos de irrigação contínuo e intermitente, não havendo diferenças significativas nas concentrações entre tratamentos. No manejo de irrigação por banhos, foram contabilizados quatro eventos de extravasamento no total. A frequência de extravasamentos principalmente dos manejos contínuo e intermitente - deve-se à grande ocorrência de precipitações no período, estando a principal diferença entre tratamentos relacionada ao volume de água transportado. Dessa forma, neste experimento foi evidenciado que, ao utilizar práticas que promovam maior armazenamento de água, há significativa diminuição do total de agrotóxicos transportados.

$\mathrm{Na}$ avaliação da massa de herbicidas transportada para o ambiente, não foi verificada interação entre os fatores manejos de irrigação e agrotóxicos. Quanto aos manejos de irrigação, foi observado que o total de agrotóxico transportado é significativamente maior no manejo de irrigação por inundação contínua (Tabela 5), observando-se redução de 41 e 59\% para os manejos intermitente e por banhos, respectivamente. Esses resultados concordam com os obtidos por Watanabe et al. (2006, 2007) e Chang et al. (2007), os quais mencionam que a água da chuva armazenada pela irrigação intermitente minimiza perdas de água por escoamento superficial durante eventos de chuva e, por conseguinte, ocasiona menor perda de agrotóxicos.

Para efetuar a comparação do transporte entre agrotóxicos, foi necessário transformar a quantidade total encontrada $\left(\mathrm{g} \mathrm{ha}^{-1}\right)$ para porcentagem do total aplicado, devido às diferenças das doses utilizadas dos agrotóxicos. Feita a transformação, verificou-se que a massa transportada para o ambiente é relativamente pequena, não ultrapassando 3\% do total aplicado (Tabela 5); contudo, em certos casos, conforme verificado no estudo de Silva et al. (2009), mesmo em pequenas quantidades, o somatório de diferentes agrotóxicos transportados simultaneamente para uma mesma bacia hidrográfica pode comprometer a qualidade da água.

Novamente, foi observado que o manejo de irrigação por inundação contínua ocasiona maior transporte por escoamento, em comparação com os demais manejos de irrigação. 
Tabela 4 - Concentração dos fungicidas trifloxystrobin e propiconazol, com respectivos intervalos de confiança (95\%), na água transportada por meio do extravasamento para fora da lavoura de arroz manejada nos sistemas de irrigação contínuo, intermitente e por banhos. Santa Maria-RS. 2009

\begin{tabular}{|c|c|c|c|c|c|c|}
\hline \multirow{2}{*}{ DAII ${ }^{1 /}$} & \multicolumn{3}{|c|}{ Trifloxystrobin $\left(\mu \mathrm{g} \mathrm{L}^{-1}\right)$} & \multicolumn{3}{c|}{ Propiconazol $\left(\mu \mathrm{g} \mathrm{L}^{-1}\right)$} \\
\cline { 2 - 7 } & Contínuo & Intermitente & Banhos & Contínuo & Intermitente & Banhos \\
\hline 75 & $4,245(+-3,124)$ & $3,325(+-5,207)$ & $--^{-}$ & $2,552(+-0,586)$ & $1,488(+-2,051)$ & - \\
\hline 83 & $1,453(+-0,539)$ & $1,773(+-0,543)$ & $\mathrm{nd}^{3 /}$ & $1,212(+-0,707)$ & $1,083(+-1,767)$ & $\mathrm{nd}$ \\
\hline 85 & $1,213(+-0,172)$ & $\mathrm{nd}$ & $2,339(+-1,831)$ & $1,636(+-0,061)$ & $\mathrm{nd}$ & $1,248(+-1,122)$ \\
\hline 90 & $0,824(+-0,206)$ & $0,943(+-0,162)$ & $0,760(+-0,609)$ & $0,981(+-0,375)$ & $1,289(+-0,401)$ & $0,612(+-0,537)$ \\
\hline 94 & $0,476(+-0,079)$ & $0,697(+-0,127)$ & $0,130(+-0,158)$ & $0,665(+-0,297)$ & $0,998(+-0,240)$ & $0,260(+-0,106)$ \\
\hline Média & 1,642 & 1,864 & 1,121 & 1,409 & 1,341 & 0,759 \\
\hline
\end{tabular}

${ }^{1 /}$ Dias após o início da irrigação; ${ }^{2 /}$ Sem ocorrência de extravasamento; ${ }^{3 /}$ nd $=$ Não detectado pelo método utilizado.

Tabela 5 - Massa total de clomazone, imidacloprid, thiamethoxam, trifloxystrobin e propiconazol transportados e porcentagem destes em relação ao total aplicado nos sistemas de irrigação contínuo, intermitente e por banhos. Santa Maria-RS. 2009

\begin{tabular}{|c|c|c|c|c|c|c|}
\hline Tratamento & Clomazone & Imidacloprid & Thiamethoxam & Trifloxystrobin & Propiconazol & Média \\
\hline \multicolumn{7}{|c|}{ Massa total dos ingredientes ativos transportados $\left(\mathrm{g} \mathrm{ha}^{-1}\right)^{\frac{1}{\prime}}$} \\
\hline Contínuo & 0,547 & 0,180 & 0,385 & 2,593 & 2,648 & $1,270 \mathrm{a}^{2}$ \\
\hline Intermitente & 0,334 & 0,051 & 0,071 & 1,474 & 1,819 & $0,750 \mathrm{~b}$ \\
\hline Banhos & 0,447 & 0,099 & 0,041 & 1,097 & 0,905 & $0,518 \mathrm{~b}$ \\
\hline Média & B 0,443 & B 0,101 & B 0,165 & A 1,721 & A 1,791 & \\
\hline \multicolumn{7}{|c|}{ 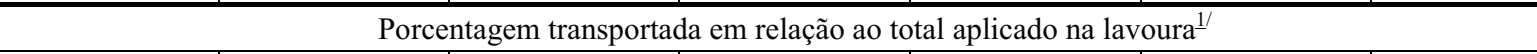 } \\
\hline Contínuo & 0,521 & 0,018 & 0,802 & 2,765 & 2,825 & $1,482 \mathrm{a}$ \\
\hline Intermitente & 0,318 & 0,005 & 0,148 & 1,572 & 1,940 & $0,725 \mathrm{~b}$ \\
\hline Banhos & 0,426 & 0,010 & 0,085 & 1,170 & 0,965 & $0,541 \mathrm{~b}$ \\
\hline Média & B 0,421 & B 0,011 & B 0,345 & A 1,836 & A 1,910 & \\
\hline
\end{tabular}

1/ Para a análise, os dados foram transformados para $y t=a \sin \sqrt{(y+0.5) / 100}$. 2/ Médias seguidas de mesma letra na linha diferem estatisticamente pelo teste de Tukey $(P \leq 0,05)$.

Nesse sentido, quando comparadas com a irrigação contínua, as irrigações intermitente e por banhos permitem redução do percentual de transporte em 39 e 18\% para clomazone; 72 e $45 \%$ para imidacloprid; 82 e $89 \%$ para thiamethoxam; 43 e $58 \%$ para trifloxystrobin; e 31 e $66 \%$ para propiconazol, respectivamente (Tabela 5). Esses resultados foram semelhantes aos encontrados por Watanabe et al. (2007), ao observarem que o emprego da irrigação intermitente propiciou redução do total de herbicida aplicado de 37 para 3,8\%, 12 para $1,2 \%$ e 35 para $2,7 \%$, ou seja, a irrigação intermitente, em comparação à contínua, proporcionou redução de 90, 90 e 92\% de transporte de simetryn, thiobencarb e mefenacet, respectivamente.

A utilização das irrigações intermitente e por banhos proporciona maior armazenamento de água da chuva no interior da lavoura, o que possibilita redução no volume de água perdida por extravasamento e, consequentemente, redução da massa de agrotóxicos transportados para o ambiente. O manejo de irrigação não afeta a meia-vida de dissipação em água do clomazone. Devido à detecção de traços de agrotóxicos durante todo o período de monitoramento, deve-se evitar o extravasamento por todo o período de cultivo do arroz, sobretudo nos períodos próximos à aplicação dos agrotóxicos.

\section{AGRADECIMENTOS}

Ao CNPq, pelo financiamento do experimento através dos Editais: MCT/CNPq 14/ 2008 - Universal, processo 471403/2008-3Universal e MCT/CNPq/CT-HIDRO/SEAP-PR número 035/2007. 


\section{LITERATURA CITADA}

BELDER, P. et al. Effect of water-saving irrigation on rice yield and water use in typical lowland conditions in Asia. Agric. Water Manag., v. 65, n. 3, p. 193-210, 2004.

BORRELL, A.; GARSIDE, A.; FUKAI, S. Improving efficiency of water use for irrigated rice in a semi-arid tropical environment. Field Crop Res., v. 52, n. 3, p. 231-248, 1997.

BORTOLUZZI, E. C. et al. Contaminação de águas superficiais por agrotóxicos em função do uso do solo numa microbacia hirográfica de Agudo RS. R. Bras. Eng. Agric. Amb., v. 10, n. 4, p. 881-887, 2006.

BRETAUD, S.; TOUTANT, J. P.; SAGLIO, P. Effects of carbofuran, diuron, and nicosulfuron on acetylcholinesterase activity in goldfish (Carassius auratus). Ecotoxicol. Environ. Saf., v. 47, n. 2, p. 117-124, 2000.

CHANG, Y. C. et al. Enhancement of water storage capacity in wetland rice fields through deepwater management practice. Irrig. Drain., v. 56, n. 1, p. 79-86, 2007.

COUNCE, P. A. et al. A uniform, objective, and adaptative system for expressing rice development. Crop Sci., v. 40, n. 2 , p. $436-443,2000$.

GRUTZMACHER, D. D. et al. Monitoramento de agrotóxicos em dois mananciais hídricos no sul do Brasil. R. Bras. Eng. Agric. Amb., v. 12, n. 6, p. 632-637, 2008.

HARPER, S. Sorption-desorption and herbicide behavior in soil. Rev. Weed Sci., v. 6, n. 1, p. 207-225, 1994.

INSTITUTO RIOGRANDENSE DO ARROZ - IRGA, 2009. Disponível em: $<$ http://www.irga.rs.gov.br/ index.php?action $=$ dados_safra_detalhes\&cod_dica $=173>$. Acesso em: 10 jan. 2010.

MARCHEZAN, E. et al. Rice herbicides monitoring in two Brazilian rivers during the rice growing season. Sci. Agric., v. 64, n. 2 , p. 131-137, 2007.

NAKANO, Y. et al. A study on pesticide runoff from paddy fields to a river in rural region-1: field survey of pesticide runoff in the Kozakura river, Japanese Water Res., v. 38, n. 13 , p. $3017-3022,2004$.

PHONG, T. K. et al. Behavior of simetryn and thiobencarb in rice paddy lysimeters and the effect of excess water storage depth in controlling herbicide run-off. Weed Biol. Manag., v. 8 , n. 4 , p. $243-249,2008$.

PHONG, T. K. et al. Fate and transport of nursery-boxapplied tricyclazole and imidacloprid in paddy fields. Water, Air Pollut., v. 202, n. 1-4, p. 3-12, 2009.
QUAYLE, W. C.; OLIVER, D. P.; ZRNA, S. Field dissipation and environmental hazard assessment of clomazone, molinate, and thiobencarb in Australian rice culture. J. Agric. Food

Chem., v. 54, n. 19, p. 7213-7220, 2006.

SANTOS, F. M. et al. Persistência dos herbicidas imazethapyr e clomazone em lâmina de água do arroz irrigado. Planta Daninha, v. 26, n. 4, p. 875-881, 2008.

SENSEMAN, S. A. (Ed.). Herbicide handbook. 9.ed. Lawrence: Weed Science Society of America, 2007. 458 p.

SILVA, D. R. O et al. Monitoramento de agrotóxicos em águas superficiais de regiões orizícolas no sul do Brasil. Ci. Rural, v. 39, n. 9, p. 2383-2389, 2009.

SOCIEDADE SUL-BRASILEIRA DE ARROZ IRRIGADO - SOSBAI. Arroz irrigado: recomendações técnicas da pesquisa para o Sul do Brasil. Pelotas: 2007. 161 p.

STONE, L. F. Eficiência do uso da água na cultura do arroz irrigado. Santo Antônio de Goiás: Embrapa Arroz e Feijão, 2005. 48 p.

TABBAL, D. F. et al. On-farm strategies for reducing water input in irrigated rice: case studies in the Philippines. Agric. Water Manag., v. 56, n. 2, p. 93-112, 2002.

TOESCHER, C. F.; RIGHES, A. A.; CARLESSO, R. Volume de água aplicada e produtividade do arroz sob diferentes métodos de irrigação. R. Fac. Zoot. Vet. Agr., v. 4, n. 1, p. $75-79,1997$.

TOMLIN, C. D. S. The pesticide manual, 13.ed. Versão 3.0. Londres: 2003/2004.

TUONG, T. P.; BHUIYAN, S. I. Increasing water-use efficiency in rice production: farm-level perspectives. Agric. Water Manag., v. 40, n. 1, p. 117-122, 1999.

TUONG, T. P.; BOUMAN, B. A. M.; MORTIMER, M. More rice, less water - Integrated approaches for increasing water productivity in irrigated rice-based systems in Asia. Plant Prod. Sci., v. 8, n. 3, p. 231-241, 2005.

WALKER, S. H. Causes of high water losses from irrigated rice fields: field measurements and results from analogue and digital models. Agric. Water Manag., v. 40, n. 1, p. 123-127, 1999.

WATANABE, $\mathrm{H}$. et al. Effect of water management practice on pesticide behavior in paddy water. Agric. Water Manag., v. 88, n. 1-3, p. 132-140, 2007.

WATANABE, H.; KAKEGAWA, Y.; VU, S. H. Evaluation of the management practice for controlling herbicide runoff from paddy fields using intermitente and spilloverirrigation schemes. Paddy Water Environ., v. 4, n. 1, p. 21-28, 2006. 